\title{
Development
}

\section{of a Patient-Centered}

Framework for Oncology

Clinicians to Address

Uncertainty in Cancer Care

During the COVID-19 Pandemic

Natasha Dhawan, $M D^{1}$

Eric Prommer, $M D^{2}$

Christian T. Sinclair, $M D^{3}$

Ishwaria M. Subbiah, $M D^{4, *}{ }^{*}$

\author{
Address \\ ${ }^{1}$ Department of Hematology and Oncology, Dartmouth-Hitchcock Medical Center, \\ Lebanon, NH, USA \\ ${ }^{2}$ Division of Hospice and Palliative Medicine, Veterans Affairs/University of Cali- \\ fornia Los Angeles, Los Angeles, CA, USA \\ ${ }^{3}$ Division of Palliative Medicine, University of Kansas Medical Center, Kansas City, \\ KS, USA \\ ${ }^{*}, 4$ Division of Palliative Rehabilitation and Integrative Medicine, Division of \\ Cancer Medicine, University of Texas MD Anderson Cancer Center, 1515 Holcombe \\ Blvd, Unit 1414, Houston, TX, 77030, USA \\ Email: isubbiah@mdanderson.org
}

Published online: 29 0ctober 2020

(C) Springer Science+Business Media, LLC, part of Springer Nature 2020

Keywords Communication strategies · Prognostication · COVID-19 · Pandemic · Shared decision-making

\section{A Note from the Editor-in-Chief:}

Clearly, we are living through extraordinary and challenging times as we confront the COVID-19 pandemic. Although we rarely publish commentaries within Current Treatment Options in Oncology, I felt that it was very important to include this particular Commentary as it reflects on the many additional challenges faced by cancer patients and their caregivers as a result of COVID-19. It also explores the possibility of long-term positive impact on patient care arising from efforts to address those challenges.

It is our hope that readers of this Commentary will find it helpful as they seek to explore productive paths through the complexities of COVID-19 in an at-risk population.

-Dr. David S. Ettinger, MD 


\section{Impact of COVID-19 on cancer care}

The SARS coronavirus 2 and the associated disease, Coronavirus Disease 2019 (COVID-19), have brought about an unprecedented level of disruption to the healthcare delivery models. In the context of oncology, clinicians and patients face decisions regarding oncologic care that require them to reconcile the impact of the risk of exposure and development of COVID-19 on the life-altering diagnosis of cancer. Initially, there was significant concern that patients undergoing active cancer therapy who later contracted COVID-19 would have worse outcomes compared with the general population. Indeed, the TERAVOLT study demonstrated a mortality rate of $34.6 \%(66 / 191)$ in patients with thoracic malignancies who contracted COVID-19, although many of these patients were not admitted to the intensive care unit (and thus did not receive ventilator support) for unknown reasons [1]. However, additional data demonstrated that patients admitted with COVID-19related illnesses had a mortality rate of $14.6 \%$ among the cohort of patients who had cancer when compared with those who did not [2]. In light of these outcomes, clinical stakeholders are rapidly developing strategies to deliver oncologic care safely with minimal exposure [3-6]. However, these approaches are in their nascency, while the traditional face-to-face model of care remains significantly altered. As a result, considerable uncertainty pervades the delivery of cancer care to every patient, including cancer-related procedures that are deemed elective; this applies as well to visitation restrictions. Recognizing the challenges and complications that we all face as a result of the impact of COVID-19, we explore practical strategies for clinicians to employ in conversations with patients, caregivers, and family to help palliate the distress from uncertainty governing their cancer care.

\section{Managing uncertainty for patients and caregivers}

Inherent to the diagnosis itself, cancer comes with a burden of uncertainty: prognosis, treatment options, treatment outcomes, toxicities, and personal and family coping. Adding a global pandemic to this milieu of human suffering brings unparalleled levels of uncertainty, resulting in added distress felt by the patient/ caregiver units. Several themes centering around uncertainty have emerged from clinical interactions with patients and caregivers during the past several months. These issues outlined in Fig. 1 span across cancer types and weave this unifying thread of concern among patients regardless of their nationalities or means.

Patients and families report that communication about a prognosis, even prognostic uncertainty, is a desirable component of patient-centered care, when potential outcomes are framed while allowing room for hope [7, 8]. Employing communication guidelines developed in the domains of palliative care allows a clinician to engage multidisciplinary teams while providing safe, supportive connections for patients and their families [9]. Families report an increased level of satisfaction with communication and the care delivered as well as an appreciation for knowing that a patient was "sick enough to die." [10] 


\section{COMMON CONCERNS EXPRESSED BY PATIENTS AND CAREGIVERS}

\section{DURING THE COVID-19 PANDEMIC}

- Continued work-up of cancer while minimizing COVID-19 exposure.

- Unanticipated modifications to cancer treatment plans (e.g., postponement of surgical resection, delay in port placement, etc.).

-Social distancing from the support system of extended family/friends.

-Access to cancer clinical trials during travel restrictions.

- Loss of employment and health insurance, financial insecurity.

-Increased domestic responsibilities (e.g., childcare, home maintenance).

-Disruption to meaningful plans (e.g., major family events, etc.).

-Continued presence of COVID-19 in the community at large.

Fig. 1. Common concerns expressed by patients and caregivers during the COVID-19 pandemic.

\section{Managing uncertainty for clinicians}

As an entirely new disease entity, COVID-19 brings its associated uncertainties regarding immediate and long-term sequelae to patients, including more complex prognostication of the trajectory of various malignancies. Oncologists engage in shared clinical decision-making with patients by utilizing a data-driven approach founded on randomized, controlled trials and real-world evidence. However, this traditional paradigm of care is challenged by the disease-modifying effects of COVID-19 (both known and unknown), leading to a distortion of standard risk and benefit analyses (outlined in Fig. 2) [4, 11-14]. Communicating the impact of these uncertainties on illness trajectory and modifications to cancer treatment plans generates a new dimension of clinician distress.

The unparalleled uncertainty of the COVID-19 pandemic underscores the need for personalized, effective, problem-focused communication strategies. It is essential that front-line oncology teams immediately deploy such strategies to mitigate

\section{COMMON CONCERNS THAT ONCOLOGISTS ARE FACED WITH DURING THE COVID-19 PANDEMIC}

-Prioritizing patient care by malignancy type and treatment intent (e.g., emergent vs. adjuvant therapy, curative vs. palliative, palliative symptom management, etc.). ${ }^{4}$

-Balancing benefits of treatment with risk of potential exposure to COVID-19. ${ }^{11}$

-Diverting from current oncologic standards of care to minimize risk of exposure (e.g., oral instead of intravenous chemotherapy, hormonal treatments, monotherapy vs. combination therapy)..$^{12}$

-Managing treatment side effects and their effects on quality of life while minimizing physical contact. ${ }^{11}$

-Discussing the uncertainty regarding the impact of COVID-19 on patients with cancer (e.g., increased susceptibility to infection, overlapping toxicities, increased symptom burden). ${ }^{13}$

-Considering re-traumatization of patients with historical/predisposition for healthcare disparities. ${ }^{4}$

-Ensuring equity in healthcare access for patients with cancer in whom other medical diagnoses may develop. ${ }^{13}$

Fig. 2. Common concerns facing oncology clinicians during the COVID-19 pandemic. 


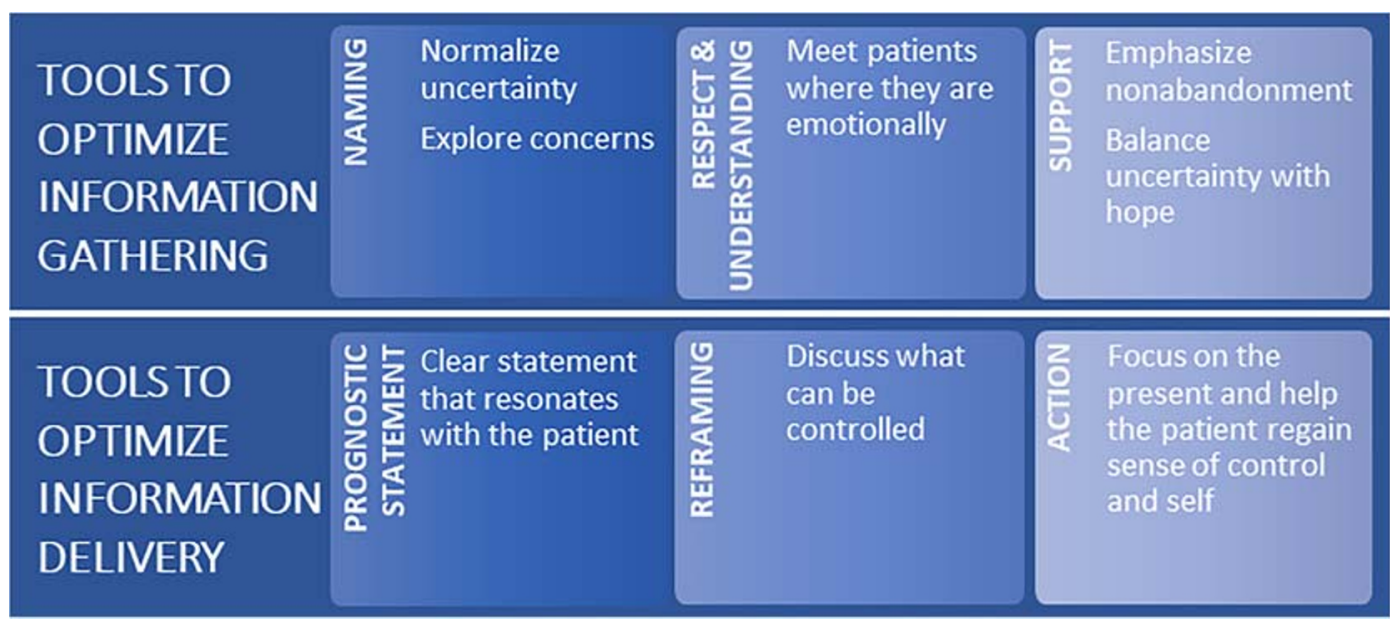

Fig. 3. Communications principles guiding conversations on clinical uncertainty.

the distress associated with disruption to the standards of care. To that end, existing communication models offer a framework for guiding clinicians through the process of rapport-building during serious illness conversations. One such framework, VitalTalk's NURSE statements (Naming, Understanding, Respecting, Supporting, and Exploring), provides a backbone of communication pertinent to many common clinical settings encountered in cancer care [15]. The fundamentals of the NURSE statements provide tools for clinicians to enable rapport-building and support of patients to optimize information gathering. These tools can then be built upon to concurrently gather information to identify a patient's prevailing sources of distress (as outlined in Fig. 3). The transition from information gathering to information delivery can be especially challenging if definitive answers to patient concerns are not available, at least at that point in time. Therefore, in addition to sharing broadly pertinent prognostic information, clinicians can deploy the strategy of reframing to help patients and their families maintain control by affirming what is certain. The framework discussed in detail in Table 1 adapts the approach previously developed for difficult conversations to now guide clinicians in their management of COVID-19-related uncertainty.

\section{Future implications}

The exceptional circumstances of the COVID-19 pandemic have accelerated changes in the healthcare delivery landscape. Patient-centered innovations that have been under discussion for decades (such as the broad implementation of telehealth) are being widely deployed at a rapid pace. Concurrently, clinical investigators continue to explore the real-world evidence to better understand the implications of this disruptive event on oncologic outcomes [12]. For patients, uncertainty has continued to be a pervasive presence throughout their cancer treatment journey, whether it is uncertainty over the likelihood of treatment response, risks of long-term recurrence, etc. The added dimension of disruptions to their cancer care during this pandemic now provides clinicians rare glimpses into this uncertain existence and the opportunity to mitigate their suffering through the direct management of this uncertainty. 
Table 1. Strategies for managing uncertainty in clinical conversations during COVID-19 pandemic (Adapted from VitalTalk) [15]

\begin{tabular}{|c|c|c|}
\hline Tools & Components & Examples \\
\hline $\begin{array}{l}\text { Naming: } \\
\text { Identifying emotions to bring them } \\
\text { to the forefront and allow for } \\
\text { exploration [15] }\end{array}$ & $\begin{array}{l}\text { - Elicit patient's understanding of } \\
\text { illness } \\
\text { - Name the prognostic uncertainty } \\
\text { - Normalize uncertainty } \\
\text { - Acknowledge the emotional toll of } \\
\text { uncertainty } \\
\text { - Explore specific concerns of patients } \\
\text { and families }\end{array}$ & $\begin{array}{l}\text { "What have you heard about COVID-19?" } \\
\text { "How has COVID-19 impacted you?" } \\
\text { "How do you think it may impact you in the } \\
\text { future?" } \\
\text { "This uncertainty can add stress on top of } \\
\text { everything cancer-related." }\end{array}$ \\
\hline $\begin{array}{l}\text { Respect and understanding: } \\
\text { Responding to a patient's emotions } \\
\text { to help relieve distress [16] }\end{array}$ & $\begin{array}{l}\text { - Lean into the uncertainty of the } \\
\text { situation and meet patients } \\
\text { where they are emotionally }\end{array}$ & $\begin{array}{l}\text { "I cannot imagine how hard this must be." } \\
\text { "Thank you for sharing your worries with me. } \\
\text { COVID-19 has impacted people in a number of } \\
\text { ways; this helps me better understand what you } \\
\text { are experiencing." }\end{array}$ \\
\hline $\begin{array}{l}\text { Support: } \\
\text { Managing the negative } \\
\text { consequences of uncertainty (e.g., } \\
\text { loss of control, emotional distress) }\end{array}$ & $\begin{array}{l}\text { - Reinforce what is certain: support } \\
\text { from family, friends, and medical } \\
\text { team }\end{array}$ & $\begin{array}{l}\text { "We will do our best to make sure you have what } \\
\text { you need." } \\
\text { "We are with you every step of the way" }\end{array}$ \\
\hline $\begin{array}{l}\text { Prognostic statement: } \\
\text { Ensuring an accurate understanding } \\
\text { and aid in decision-making even } \\
\text { during uncertainty }\end{array}$ & $\begin{array}{l}\text { - Prognostic statements about } \\
\text { uncertainty can frame the } \\
\text { possibility of hope [8] } \\
\text { - The medical team must deliver the } \\
\text { same prognostic information to } \\
\text { minimize further uncertainty }\end{array}$ & $\begin{array}{l}\text { "I hope ... and I worry..." statements } \\
\text { "Best case, worst case, and most likely" scenarios } \\
\text { [17] }\end{array}$ \\
\hline $\begin{array}{l}\text { Reframing: } \\
\text { Holding the uncertainty of the } \\
\text { situation while moving forward in } \\
\text { decision-making }\end{array}$ & $\begin{array}{l}\text { - Reframing the situation by } \\
\text { acknowledging what is certain } \\
\text { - Aggressive symptom management } \\
\text { - Continued support from an } \\
\text { interdisciplinary team }\end{array}$ & $\begin{array}{l}\text { "I wonder if it would be helpful to discuss what } \\
\text { we are certain about?" } \\
\text { "I wish things were different. Although there is a } \\
\text { lot up in the air with COVID-19, there are some } \\
\text { things we can try that may help you." }\end{array}$ \\
\hline $\begin{array}{l}\text { Action: } \\
\text { Focusing on the present to help } \\
\text { patients with meaning-making and } \\
\text { regaining control }\end{array}$ & $\begin{array}{l}\text { - List items that can be "done" (e.g., } \\
\text { advanced care, estate, and legacy } \\
\text { planning) } \\
\text { - Differentiating physical from social } \\
\text { distancing } \\
\text { - Give permission to reach out to } \\
\text { friends and family } \\
\text { - Engage interdisciplinary team. }\end{array}$ & $\begin{array}{l}\text { "Let us work together to come up with a list of } \\
\text { goals that you and your family can achieve } \\
\text { now, during COVID-19." }\end{array}$ \\
\hline
\end{tabular}

\section{Funding}

Dr Ishwaria M. Subbiah received support from the American Cancer Society, the Andrew Sabin Family Foundation, and the Gabrielle's Angel Foundation for Cancer Research. 


\section{Compliance with Ethical Standards}

\section{Conflict of interest}

Natasha Dhawan declares that she has no relevant conflict of interest. Eric Prommer declares that he has no conflict of interest. Christian T Sinclair declares that he has no relevant conflict of interest. Ishwaria M. Subbiah declares that she has no relevant conflict of interest.

\section{References and Recommended Reading}

1. Garassino MC, Whisenant JG, Huang L-C, Trama A, Torri V, Agustoni F, et al. COVID-19 in patients with thoracic malignancies (TERAVOLT): first results of an international, registry-based, cohort study. The Lancet Oncology. 2020;21:914-22.

2. $\quad$ Barlesi F FS, Bayle A, et al.: Outcome of cancer patients infected with COVID-19, including toxicity of cancer treatments American Association for Cancer Research (AACR) Virtual Annual Meeting I, 2020.

3. Banna G, Curioni-Fontecedro A, Friedlaender A, et al. How we treat patients with lung cancer during the SARS-CoV-2 pandemic: primum non nocere. ESMO Open. 2020;5.

4. Hanna TP, Evans GA, Booth CM. Cancer, COVID-19 and the precautionary principle: prioritizing treatment during a global pandemic. Nat Rev Clin Oncol. 2020;17:268-70.

5. Motlagh A, Yamrali M, Azghandi S, Azadeh P, Vaezi M, Ashrafi F, et al. COVID19 prevention \& care a cancer specific guideline. Arch Iran Med. 2020;23:255-64.

6. Shankar A, Saini D, Roy S, Mosavi Jarrahi A, Chakraborty A, Bharti SJ, et al. Cancer care delivery challenges amidst coronavirus disease - 19 (COVID19) outbreak: specific precautions for cancer patients and cancer care providers to prevent spread. Asian Pac J Cancer Prev. 2020;21:569-73.

7. Evans LR, Boyd EA, Malvar G, Apatira L, Luce JM, Lo B, et al. Surrogate decision-makers' perspectives on discussing prognosis in the face of uncertainty. Am J Respir Crit Care Med. 2009;179:48-53.

8. Glare PA, Sinclair CT. Palliative medicine review: prognostication. J Palliat Med. 2008;11:84-103.
9. Chochinov HM. Thinking outside the box: depression, hope, and meaning at the end of life. J Palliat Med. 2003;6:973-7.

10. Krawczyk M, Gallagher R. Communicating prognostic uncertainty in potential end-of-life contexts: experiences of family members. BMC Palliat Care. 2016;15:59.

11. Schrag D, Hershman DL, Basch E: Oncology practice during the COVID-19 pandemic. Jama, 2020.

12. Van de Haar J, Hoes LR, Coles CE, et al. Caring for patients with cancer in the COVID-19 era. Nat Med. 2020;26:665-71.

13. Bersanelli M. Controversies about COVID-19 and anticancer treatment with immune checkpoint inhibitors. Immunotherapy. 2020;12:269-73.

14. Yancy CW: COVID-19 and African Americans. Jama, 2020.

15. VitalTalk: Responding to emotion: respecting, 2019.

16. Smith AK, White DB, Arnold RM. Uncertainty-the other side of prognosis. N Engl J Med. 2013;368:244850.

17. Kiely BE, Tattersall MH, Stockler MR. Certain death in uncertain time: informing hope by quantifying a best case scenario. J Clin Oncol. 2010;28:2802-4.

\section{Publisher's note}

Springer Nature remains neutral with regard to jurisdictional claims in published maps and institutional affiliations. 